\title{
Engaging stakeholders to identify implementation strategies for a faith-based physical activity program
}

Jessica Haughton ( $\nabla$ jhaughton@sdsu.edu )

San Diego State University https://orcid.org/0000-0002-6555-3162

Michelle L. Takemoto

ServiceNow

Jennifer Schneider

Institute for Behavioral and Community Health, San Diego State University

Steven P. Hooker

College of Health and Human Services, San Diego State University

Borsika Rabin

Department of Family Medicine and Public Health, University of California San Diego

Ross C. Brownson

Prevention Research Center in Saint Louis, Brown School, Washington University in Saint Louis

Elva M. Arredondo

School of Public Health, San Diego State University

\section{Research}

Keywords: Health promotion, faith-based, physical activity, Latinos/Hispanics, stakeholders, evidence-based interventions, implementation strategies, scale-up, dissemination, qualitative

Posted Date: February 19th, 2020

DOI: https://doi.org/10.21203/rs.2.23928/v1

License: (c) (i) This work is licensed under a Creative Commons Attribution 4.0 International License. Read Full License 


\section{Abstract}

Background Stakeholder engagement is critical to the acceleration of evidence-based interventions into community settings. Harnessing the knowledge and opinions of community stakeholders increases the likelihood of successful implementation, scale up, and sustainment of evidence-based interventions. Faith in Action ( Fe en Acción) is an evidence-based promotora -led physical activity program designed to increase moderate-to-vigorous physical activity among churchgoing Latina women.

Methods We conducted in-depth interviews using a semi-structured interview guide based on the Consolidated Framework for Implementation Research (CFIR) at various Catholic and Protestant churches with large Latino membership in San Diego County, California to explore barriers and facilitators to implementation of a Faith in Action and to identify promising implementation strategies for program scaleup and dissemination. We interviewed 22 pastors and church staff and analyzed transcripts using an iterative-deductive team approach.

Results Stakeholders described barriers and facilitators to implementation within three domains of CFIR: characteristics of individuals (lack of self-efficacy for and knowledge of PA; influence on churchgoers' behaviors), inner setting (church culture and norms, alignment with mission and values, competing priorities, lack of resources), and outer setting (need for buy-in from senior leadership). From the interviews, we identified four promising implementation strategies for the scale-up of faith-based health promotion programs: 1) health behavior change training for pastors and staff; 2) tailored messaging; 3) developing community collaborations; and 4) gaining denominational support.

Conclusions While churches can serve as valuable partners in health promotion, specific barriers and facilitators to implementation must be recognized and understood. Addressing these barriers through targeted implementation strategies at the adopter and organizational level can facilitate improved program implementation and lead the way for scale-up and dissemination.

\section{Contributions To The Literature}

- This research examines the barriers and facilitators to implementation of a faith-based promotora-led physical activity promotion program.

- The Consolidated Framework for Implementation Research (CFIR) was used to identify factors affecting program implementation of health promotion programs in faith-based settings.

- Findings provide specific suggestions on implementation strategies for scale-up of health promotion programs in faith-based settings.

\section{Introduction}

Despite the well-established evidence for physical activity (PA) in the prevention and control of cancer and other chronic diseases, approximately $80 \%$ of US adults and adolescents are insufficiently active. ${ }^{1-4}$ In particular, Latinas only $13.6 \%$ of Latinas meet the PA guidelines, compared to $22 \%$ of non-Latina white 
women. ${ }^{5}$ Furthermore, Latinas engage in fewer total minutes of PA than Latino men (19 vs. $30 \mathrm{~min} / \mathrm{day}$ ). ${ }^{6}$ Dissemination and implementation of evidence-based PA programs are needed to help mitigate health disparities among Latinas and other at risk groups. ${ }^{7}$

Faith-based organizations (FBOs) provide a unique setting to implement evidence-based interventions (EBIs) and are increasingly recognized as important partners in Latino-focused health promotion efforts, including physical activity. ${ }^{8-12}$ The strong connection between health messages and the spiritual mission of the FBO, in addition to its reach into underserved communities, further justify the church as an effective health promotion setting. ${ }^{13,14}$ Studies have documented the effectiveness of health promotion programs in FBOs; however, significant gaps exist in translating EBls into faith-based settings to have broader reach. ${ }^{15,16}$ Understanding the contextual factors is a critical step in translating research to practice, particularly in community settings. ${ }^{17}$ Engaging stakeholders in the process of translation can lead to more effective assessments of contextual factors influencing implementation, and therefore more effective translation of behavioral interventions. ${ }^{18}$

Faith in Action (Fe en Acción) is a faith-based multi-level promotora-led intervention promoting moderate-tovigorous PA (MVPA) among Latina women through group PA classes and Motivational Interviewing calls. ${ }^{19,20}$ Its effectiveness was tested using a cluster randomized controlled trial in 16 churches. ${ }^{21}$ At 12 months, there were significant increases in accelerometer-based MVPA and self-report leisure-time MVPA among Latinas in the intervention versus comparison condition, which suggests a greater increase in PA than many other PA interventions. ${ }^{22}$ Intervention participants, compared to those in the attention-control condition, had a $66 \%$ higher odds of meeting the PA guidelines, reduced BMI, and used more behavioral strategies for engaging in PA. Attendance to PA classes was associated with increased self-report leisuretime MVPA; number of Motivational Interviewing calls was associated with meeting the PA guidelines. There were approximately 25,000 attendees in 8 intervention churches over the course of the 5-year study. Efficacy-effectiveness trials have promoted PA in FBOs, but Faith in Action is the only one that has focused on Latinas. ${ }^{23-26}$

Because the outcomes paper focused on participant outcomes, little is known of how the organizational context contributed to the success (the "how" and the "why"). Understanding the organizational context is critical for scale-up and dissemination of evidence-based programs. ${ }^{27}$ Midway through the implementation of Faith in Action, we collected data examining implementation outcomes of a subset of churches participating in the physical activity intervention. ${ }^{28}$ The findings suggest that pastor support, innovationvalues fit, and resource availability were factors that impacted implementation effectiveness (average 6month participation rates in PA classes at each church). In addition, churches with lower parishioner engagement had low support from church staff and leaders while churches with higher parishioner engagement reported high pastor support, high innovation-values fit, medium to high recourse availability, and medium to high parishioner engagement. ${ }^{28}$ While these findings shed light on the organizational-level factors affecting implementation of Faith in Action, more targeted studies are needed identify determinants that impact implementation and implementation strategies that target these determinants among a wider range of religious denominations for wider scale-up and dissemination. 
While churches are promising venues for health promotion programs, ${ }^{29-32}$ including PA interventions, $8,11,33-36$ the lack of understanding of organizational context and determinants for implementation and sustainment limit dissemination capability for these programs. Few faith-based health promotion studies have been taken to scale and ${ }^{37,38}$ most have targeted African-American

populations, ${ }^{37,39,40}$ and only a few have targeted PA as a main outcome, with limited effectiveness. ${ }^{8,35}$ Webb and colleagues explored faith leaders' perceptions of health and wellness; however, their sample was entirely Caucasian and majority Methodist, and did not focus on the implementation of a particular program. ${ }^{41}$ Finally, few faith-based studies have systematically explored the perspectives of stakeholders regarding barriers and facilitators to implementation. Bernhart and colleagues administered surveys to pastors of churches participating in the Faith, Activity, and Nutrition (FAN) program, however the sample was comprised of churches with predominantly African-American membership. ${ }^{42}$ The authors acknowledged the limitations of survey data and reported that in-depth interviews would have further elucidated the findings, explaining the mechanisms behind the barriers and facilitators to implementation.

The objective of this study is to examine factors associated with the implementation and sustainment of an evidence-based PA intervention (Faith in Action) through stakeholder interviews and identify implementation strategies specific to the church context to inform future program scale-up and dissemination.

\section{Methods}

\section{Study Design}

We conducted a qualitative study consisting of 18 semi-structured interviews $(n=10$ at six Catholic Churches and $n=8$ at eight Protestant Churches) with 22 stakeholders to identify barriers and facilitators to implementation and sustainment of an evidence-based, faith-based PA intervention in Latino churches. The study received approval from the Institutional Review Board at San Diego State University.

\section{Theoretical framework}

The semi-structured interview guide was developed using the Consolidated Framework for Implementation Research (CFIR). ${ }^{43}$ This framework was chosen because it is comprehensive, examines domains influencing implementation effectiveness, and is well suited for complex, multilevel interventions. ${ }^{44,45}$ Openended questions assessing all five CFIR domains (intervention characteristics, inner setting, outer setting, process, and characteristics of individuals) were adapted from those presented in the online interview guide tool (cfirguide.org) to assess implementation and the domains from Schell and colleagues ${ }^{46}$ to assess sustainability. While the domains and constructs included in the CFIR are more oriented towards a healthcare setting, there are few options of frameworks aimed at examining best practices for health promotion in faith-based settings. ${ }^{47}$ The questions were adapted to fit non-clinical settings, simplifying language to make it relevant for community-based settings and incorporating appropriate Catholic or Protestant vocabulary (e.g., parishioner, churchgoer, priest, pastor). A copy of the interview guide has been included in the supplemental files (see Additional file 1). 


\section{Sampling and Data Collection}

To gather data on both the previous implementation of Faith in Action and potential for dissemination and scale up, we recruited pastors and staff from the 8 Catholic churches that participated in the Faith in Action intervention plus 10 Protestant churches in San Diego County serving large Latino congregations.

Protestant is the second most common denomination for churchgoing Latinos. ${ }^{48}$ These other churches were identified using online search engines (search terms "San Diego" and "Spanish church" or "iglesia") and compiled into a database of Protestant churches in San Diego County with at least one Spanishlanguage weekend service $(n=53)$. We used phone, email and mail for initial contact and follow-up, stopping at 5 contact attempts per church. In addition, research staff visited 10 churches in-person to solicit interviews, prioritizing bilingual churches with large congregations and monolingual Spanish churches. This process continued until we recruited 10 churches that represented a variety of denominations within the larger category of Protestant (i.e., Evangelical, Baptist, Seventh-Day Adventist, non-denominational), demographics, and contexts to ensure variability across sites. During recruitment we described to potential participants the purpose of the research in identifying barriers and facilitators to implementation of health programs in churches. Twenty-two pastors and staff agreed to participate.

\section{Data collection}

The majority of the interviews $(n=13)$ were conducted by $\mathrm{JH}$ (a female MPH/MA researcher with experience implementing faith-based interventions) and EA (a female PhD health behavior research). The remaining 5 were conducted by MT (a female PhD researcher with extensive qualitative experience) and JS (a female graduate student with training in qualitative methods). Several co-authors (JH, EA, MT, JS) trained in qualitative methods, conducted the interviews in pairs. Interviews were conducted in-person at the churches in either English or Spanish according to the interviewees' preference and lasted an average of 45 minutes. In some cases, more than one individual participated in an interview, resulting in 18 interviews with 22 total stakeholders. Interviews were audio-recorded, transcribed verbatim, and reviewed by the interviewer to ensure accuracy. Field notes were collected during the interview and added to the data file. Identifying information such as pastor names were removed or abbreviated and Spanish transcripts were translated to English using standard protocols. ${ }^{49}$ To ensure all aspects of the qualitative research was reported, the consolidated criteria for reporting qualitative studies (COREQ) ${ }^{50}$ was used as a checklist (see Additional file 2).

\section{Data Analysis}

Data were analyzed and coded using an iterative-deductive approach. MT and JH coded the first two interviews to develop preliminary codebooks guided by CFIR constructs. Transcripts were independently coded to categorize data, then discussed in person to reach consensus. ${ }^{51-53}$ The initial interview codebook was used by the larger research team (JH, MT, JS, and 6 students) to code each subsequent interview transcript. Groups of three team members, including at least one of the lead researchers (JH, MT, JS), coded each transcript independently and then met in person to discuss discrepancies until consensus was reached. As necessary, the team revised the codebook, adding codes that emerged throughout the process 
and refining definitions in the codebook for greater clarity. ${ }^{54}$ All changes were discussed and agreed upon in weekly team meetings to further ensure mutual understanding. Furthermore, consistency was ensured by repeated rounds of re-coding the same transcript after clarifying differences. After coding all transcripts, we identified sub-codes to categorize and re-categorize codes into relevant relationships. ${ }^{55} \mathrm{~A}$ detailed audit trail of codebook drafts, coded and re-coded transcripts, meeting notes, codebook edits, and resolved discrepancies was kept throughout the process. We coded all transcripts by hand and then inputted the coded data to Dedoose software (SocioCultural Research Consultants, LLC version 7.5.9) to organize and sort the data.

Once the data was coded and organized, $\mathrm{JH}$ reviewed and examined the codes, merging similar codes and separating broader ones, sorted them into themes, and selected key quotes that represented the main themes. A group discussion involving EA and MT finalized the main themes and identified the salient barriers and facilitators (see Table 1).

After identifying the barriers and facilitators to implementation and sustainment, JT and EA used the ERIC strategies ${ }^{56}$ to link and identify mechanisms of action for each implementation strategy. These were then validated by BR, a co-author with expertise in implementation science (see Table 2).

\section{Results}

\section{Description of Study Participants}

Eighteen semi-structured interviews were conducted with 22 pastors and staff between April and August 2018 out of 61 churches invited. Differences were not observed between interviews with one participant and those with two participants. Most interviews were conducted in English $(n=14)$ and the remainder in Spanish $(n=4)$. Seventeen of the interviewees were male and 5 were female. Of the 22 stakeholders who participated in the interviews, all held formal positions within their churches: 11 were senior pastors or priests, 5 were associate or assistant pastors, and 6 were paid church staff members (business managers, secretaries, and deacons). One interviewee (assistant pastor) declined to be recorded and was not included in the final analysis.

\section{Barriers and Facilitators to Implementing Faith in Action}

The barriers and facilitators identified fell within three of the five CFIR domains (i.e., characteristic of individuals, inner setting, and outer setting). We summarized major findings according to CFIR domains and included seminal quotes as illustrations of each (Table 1).

\section{Characteristics of Individuals}

Pastors and staff lack self-efficacy for and knowledge of PA. In general, pastors and staff reported having low self-efficacy for PA and lacked knowledge of PA. While a few mentioned having personal PA habits (e.g., cycling, running), most reported struggling to find time to be active and unsure of how to encourage churchgoers to be active. One pastor described his hesitancy in encouraging PA, "Well probably I'm not the 
best person to talk about that because I need it badly. I lost already 24 pounds but I need to lose another 40 pounds." Some pastors mentioned that they would feel like "hypocrites" if preaching about health, given their own challenges in maintaining healthy habits. Pastors shared that their demanding and unpredictable work schedules contribute to unhealthy habits and a lack of priority of their own health. In addition, pastors' lack of self-efficacy for PA limits their ability to motivate healthy behaviors among churchgoers.

Pastors have influence over churchgoers' behaviors. Church staff felt that pastors who were roles models for PA and healthy eating had a strong influence on churchgoers. Some pastors said they had opportunities to counsel churchgoers, but while they felt equipped in mental health counseling, they were sure about how to best encourage individuals to be physically active. One pastor described his influence over his congregation in the following way, "If I open my mouth, they'll hear. They'll listen."

\section{Inner Setting}

Churches can support a culture of overeating and unhealthy behaviors. Pastors and church staff described the important role of food in fellowship in the church. Stakeholders stated that food is often served at churches events, and lacks healthy options. One pastor told us, "There's a little saying in our Spanish 'Don't trust a skinny Pastor"' when describing the gifts of food given him by churchgoers.

Churches implement programs aligned with their mission and values. While many of the pastors and staff we interviewed acknowledged the importance of health and the need for more PA opportunities for their members, many emphasized the need for any program to align with the church's mission and values. Given that a church's mission is to build faith and share the message of God, finding a way to frame PA within that mission is essential. Once pastor said, "I think our mission is to help people to have good health physically, mentally, emotionally, and spiritually. So, that is a complement to our mission." Pastors did see an opportunity in connecting physical health with spiritual and mental health, as one shared, "the church is sometimes too spiritual, but the people do not die due to the spiritual, instead it is physical. They get sick because of physical health." Finally, pastors had the view that any new program, to be successful, would have to "nestle itself into the homeostasis of the church, so it just becomes natural."

Church culture and norms are influenced by pastors and staff. A few pastors reported having spoken about physical health from the pulpit, however most reported not having the knowledge or resources to do so. One pastor shared, "that's what I gotta get my hands on, some of these templates that tie in the scriptures with you know healthy eating and exercise and stuff like that."

Churches have many competing priorities. While pastors and staff recognized the importance of physical health and acknowledged the potential role of the church in promoting health among churchgoers, they also expressed that churches have many other important priorities. Pastors talked about kids and youth programming, marriage counseling and retreats, spiritual formation, social justice campaigns, and many other ongoing programs. In addition, pastors in more urban and low-resource communities shared about their challenges getting churchgoers to be involved in and committed to church programming given the transitional nature of their communities. 
Churches often lack sufficient space and personnel. Many of churches included in this study have small programming budgets, limited space, and few paid personnel. Pastors expressed concern about adding more to already overburdened staff and volunteers, saying, "the people who kind of are the natural leaders are already pretty spread out." Most were also concerned about the cost of program implementation and said they have little funds to spend on programming outside of faith formation activities. Others were concerned that a new program may have to compete with current programs for space.

Programs typically come from within the church. Particularly among Protestant churches, but to some extent in Catholic churches as well, most programs are implemented from within the church. Pastors described processes in which new programs are suggested by church members and leaders, vetted by the leadership, and implemented if seen as beneficial to members and sufficient resources are available. While no pastors said they would not accept an outside program, many expressed hesitancy in hosting a program from an outside organization and said they would want to hear from other pastors about their experience with Faith in Action before moving forward.

\section{Outer Setting}

Denominational support is critical for program success. In this study, pastors noted the importance of support from upper denominational leadership. Pastors of Catholic churches mentioned the importance of buy-in from the local diocese. Those in Protestant churches saw denominational support as an opportunity to disseminate the program more widely to other churches.

\section{Promising Implementation Strategies for Faith-Based Health Promotion Programs}

The following four organizational-level implementation strategies are recommended to engage pastors and church staff to improve implementation of faith-based health promotion programs. While these strategies are tailored to faith-based settings, each is based on ERIC implementation strategies ${ }^{56}$ as noted in Table 2. We also identified the proposed mechanism of action to explain how we linked barriers and facilitators to proposed implementation strategies.

1. Health Behavior Change Training for Pastors and Staff. Pastors described a lack of self-efficacy for PA and that they would feel like "hypocrites" if preaching about physical health and wellness given their lack of knowledge. They reported not know much about PA recommendations and cited very little if any education or training in health. Pastors shared that their demanding and unpredictable work schedules contribute to unhealthy habits and a lack of priority of their own health, statements that support the findings of Proeschold-Bell and McDevitt. ${ }^{57}$ The stress and burnout pastors and church staff experience can lead to negative health consequences. ${ }^{58}$ However, pastors have a strong influence over churchgoers who look to pastors as role models. ${ }^{41,58,59}$ Some spoke about their role as counselors, particularly with issues related to mental health, but admitted lacking confidence in counseling churchgoers on physical health. Our findings support the literature describing the strong influence pastors have over churchgoers' behaviors. ${ }^{58,59}$ Finally, pastors and church staff have a strong influence over the church norms and culture, which can, at times, support a culture of overeating and 
unhealthy behaviors. ${ }^{60}$ This is supported in the literature where a number of studies have found higher rates of chronic disease among faith leaders. A national study of various denominations found higher rates of physical inactivity, obesity, poor dietary habits, and chronic disease among faith leaders compared to the general US population. ${ }^{61}$ Social interactions around food have long been an important part of church culture, and often these foods are high-fat and not nutritious. ${ }^{60,62}$ While churches can have cultures that are resistant to change and act as barriers to healthy behaviors, there is promising research that churches providing instrumental support for PA through church-based PA programs see increases in PA among members. ${ }^{36}$ As important decision-makers in the church, pastors and staff have the ability to adopt programs, align them with their vision, and influence the culture and norms of the church. ${ }^{14}$ Pastors and church staff have the potential to influence church culture and norms in ways that promote health. ${ }^{59}$ Given these findings, we suggest that faith-based health promotion programs include training and education on health behavior for pastors and influential church staff be included in the intervention, even if the pastors and church staff are not the primary program implementers. We expect that if pastors and church staff are trained in health behavior change methods, they will have increased self-efficacy for PA, will be able to role model healthy behaviors including PA, will encourage churchgoers to be active and healthy, and will influence the norms and culture of the church to shift to include health-promoting policies (e.g., water to replace sugar-sweetened beverages at church events, establishing a health ministry).

2. Tailored Messaging. Interviews with pastors highlighted the importance of aligning program messaging with the FBO's mission and values, which may vary between denominations and churches. In general, pastors in the Protestant churches saw our program as an opportunity for outreach and evangelization while pastors in Catholic churches were interested in how the program could build community among current parishioners. Depending on the church's denomination and mission, the program messaging could be tailored to either of these objectives and include messages from scripture reinforcing the importance of taking care of one's health. By tailoring the messaging to each church, the program is more likely to be accepted and perceived as something integrated into the mission of the organization.

3. Fostering Community Collaborations. Only a few of the eight churches that participated in Faith in Action sustained the program beyond the study period and for those that did, collaborations with community partners were an important factor that facilitated sustainment. In addition, for those churches with fewer resources and less space to host program activities, partnerships with community organizations, including a local recreation center, facilitated implementation. Developing partnerships with organizations with missions in alignment with the health promotion program, for example, promoting PA, is expected to facilitate improved implementation and program sustainment. These collaborations could help support implementation through sharing of space for PA activities, shared personnel, or join projects to promote PA in their communities.

4. Gain Denominational Support. Churches tend to be hierarchical in structure, with the majority of the decision-making left to senior leaders. ${ }^{63}$ During interviews, pastors highlighted the need for denominational support for the program to have long-term success. For example, buy-in from bishops in the Catholic Diocese or leaders of Protestant denominational groups would validate the program. 
Given the hierarchical structure of FBOs, support of the program from upper leadership is essential for pastors and staff to implement health promotion programs in their churches.

\section{Discussion}

Identifying the barriers and facilitators to implementation by engaging community stakeholders in an essential component of community-based health promotion. This kind of "co-learning", in which researchers and community partners learn from each other, can result in more effective program implementation that addresses context-specific influences and factors. ${ }^{18}$ To our knowledge, our study is the first of its kind to examine barriers and facilitators to implementation of a faith-based PA program through interviews with pastors and church staff. Data supported the value of accounting for the inner and outer context when implementing PA programs in faith-based settings and they may vary by church size and denomination.

Data from the interviews suggest that targeting the health practices of church leaders would be a key strategy that would facilitate implementation and sustainment of health promotion programs in churches. In all religious denominations, pastors are role models and play a critical role in defining the characteristics of church life. ${ }^{64,65}$ Maton found that church groups with capable leaders reported positive group assessments and well-being and that pastors influence attendees' commitment and perceived social support. ${ }^{66}$ Increasing the self-efficacy of leaders to engage in PA and providing education on the benefits of PA could empower leaders to promote PA and create wellness policies in their congregation. Further, church leaders who role model PA may indirectly impact the health practices of their parishioners (e.g., seeing pastors make time for walks). To date, the implementation strategies used to translate EBIs in faith-based settings have primarily focused on ways stakeholders can adopt and implement program activities and less on the health practices of the stakeholders themselves. ${ }^{58,67}$ The implementation of PA programs may have more impact and be sustained by stakeholders who engage in PA within a supportive organizational climate and culture.

The results highlight the importance of tailoring messages based on church context. Each church has its own culture, norms, and values. Matching the program messages with the culture of the church could lead to improved implementation and sustainment. For example, an important value of the Seventh Day Adventist denomination is healthy living (e.g., members of this denomination practice vegetarianism). Tailored messages for a Seventh Day Adventist Church could connect their value for health with PA programming, perhaps even building health into the mission statement of the church. In addition, churches vary in their style and methods of communication. Some churches communicate programming through printed newsletters and others have sophisticated social media and web platforms. Strategies used to promote the program and invite churchgoers to participate should be tailored to the preferred communication method of each church.

Strengthening the links between churches and health organizations embedded in the larger ecosystem was another proposed strategy noted by stakeholders. Local and national organizations that promote the wellbeing of community members like parks and recreation, YMCA, Catholic Charities, and health departments may provide resources that would help churches implement and sustain health promotion programs. $68,69,70$ 
Most stakeholders reported little connection with outside organizations, but a had a desire to build those connections as important for successful implementation and sustainment. This strategy would involve increasing the capacity of pastors to establish partnerships with outside organizations who could support the implementation and sustainment of PA programs. In this role, church leaders can also connect churchgoers and community members to resources they may not otherwise have and increase the impact of community organizations.

Lastly, participants noted the value of having denominational support when implementing health programs. When considering the Catholic denomination, strong denominational support from the Diocese would support pastors in the implementation of health programs and potentially bring in resources. For instance, the pastors could request time during their monthly meetings at the Diocese to discuss how Faith in Action and other health programming is impacting their church. This would demonstrate to pastors that the Diocese supports health programming in churches and would encourage more pastors to devote time and resources to establishing health ministries and PA programs.

This study contributes to other dissemination and implementation work in faith-based settings. ${ }^{37,38,71}$ While the potential of health promotion programs in faith-based settings has been recognized, ${ }^{10,14}$ there is limited evidence on specific barriers and facilitators to program implementation by church leaders and implementers in faith-based settings. Wilcox and colleagues examined the adoption, reach, and effectiveness of a faith-based healthy eating and PA intervention (FAN) in African-American churches in South Carolina by surveying church members of the participating churches ${ }^{37}$ Another paper examined the perspectives of church leaders who participated in the FAN intervention. ${ }^{42}$ Church leaders identified barriers to program implementation including resistance to change, age of churchgoers, lack of participation, lack of time, weather, lack of leadership, and limited budget. ${ }^{42}$ Facilitators included internal support, communication, leadership, external support, health opportunities, tailoring, and champions. ${ }^{42}$ While the sample (African-American churches) and methods (survey) vary from our study with church leaders and staff of Latino churches, the barriers and facilitators echo and support our findings. Based on their findings, Bernhart and colleagues recommend providing training and technical assistance directly to church leaders and staff, which supports one of our selected implementation strategies. As noted by Leyva and colleagues, capacity building of church leaders and staff would help support adoption and implementation of health promotion programs in faith-based settings. ${ }^{72}$

\section{Limitations \& Strengths}

While the sample size meets evidence-based guidelines, ${ }^{73}$ the generalizability of the findings could be limited by the relatively small number of interviews. In addition, the findings may not be generalizable to churches that serve other communities and denominations. Of the 53 Protestant churches approached, only 10 participated in interviews. The findings may not represent the opinions of pastors and church staff who did not participate. 
The majority of published studies have focused on African-American churches and relied on survey data. ${ }^{23,37,42}$ Unique to our study is a focus on the perceptions of pastors and staff at Latino churches of a faith-based PA promotion program. Finally, data from multiple sources (pastors and church staff) from various denominations further ensured the credibility and dependability of the findings.

\section{Conclusions}

This study with FBO stakeholders about a faith-based physical activity promotion program yielded important information about barriers and facilitators to implementation and helped identify implementation strategies to employ in future work that supports scale up and sustained implementation. The findings suggest that there are a number of barriers to implementing health promotion programs in faith-based settings. Incorporating implementation strategies including training in health behavior change, tailored messaging, community collaborations, and denominational support are expected to result in improved implementation and sustained use of EBIs in FBOs.

As public health practitioners seek to partner with FBOs, addressing these key barriers and facilitators through identified implementation strategies is essential. Others working in faith-based settings can use our results to develop and design interventions that address these barriers to implementation.

\section{Abbreviations}

CFIR

Consolidated Framework for Implementation Research

COREQ

Consolidated criteria for reporting qualitative research

EBI

evidence-based intervention

FBO

faith-based organization

MVPA

moderate-to-vigorous physical activity

PA

physical activity

\section{Declarations}

\section{Acknowledgements}

We are grateful for the cooperation of church pastors and staff in addition to administrative personnel for facilitating access to churches and for their collaboration on this project.

\section{Funding}


Research reported in this publication was supported by the National Cancer Institute of the National Institutes of Health under award numbers U54CA132384 \& U54CA132379. The intervention on which this study is based was funded through the National Cancer Institute of the National Institutes of Health award R01CA138994. This project was also supported in part by the National Cancer Institute at the National Institutes of Health Mentored Training for Dissemination and Implementation Research in Cancer Program (5R25CA171994) and the US Department of Veterans Affairs and the Cancer Research Network. The findings and conclusions in this paper are those of the authors and do not necessarily represent the official position of the National Institutes of Health.

\section{Availability of data and materials}

The data that support the findings of this study are available from the corresponding author upon reasonable request.

\section{Authors' contributions}

$\mathrm{JH}, \mathrm{EA}$, and MT conceived the papers' aims and drafted and edited the manuscript. JH, MT, JS, and EA conducted the interviews and analyzed the qualitative data. EA, BR, SH, and RB reviewed earlier versions of the paper and provided critical feedback. All authors read and approved the final manuscript.

\section{Competing interests}

The authors declare that they have no competing interests.

\section{Ethics approval and consent to participate}

This research was approved the San Diego State University Institutional Review Board (\#HS-2018-0007). All participants completed informed consent prior to participation.

\section{Consent for publication}

Not applicable

\section{References}

1. Moore SC, Lee IM, Weiderpass E, et al. Association of Leisure-Time Physical Activity With Risk of 26 Types of Cancer in 1.44 Million Adults. JAMA internal medicine. 2016;176(6):816-825.

2. Kerr J, Anderson C, Lippman SM. Physical activity, sedentary behaviour, diet, and cancer: an update and emerging new evidence. The Lancet Oncology. 2017;18(8):e457-e471.

3. Services USDoHaH. Physical Activity Guidelines for Americans, 2nd edition. Washington, DC: U.S. Department of Health and Human Services; 2018.

4. Piercy KL, Troiano RP, Ballard RM, et al. The physical activity guidelines for americans. JAMA. 2018;320(19):2020-2028. 
5. Neighbors CJ, Marquez DX, Marcus BH. Leisure-time physical activity disparities among Hispanic subgroups in the United States. American journal of public health. 2008;98(8):1460-1464.

6. Arredondo EM, Sotres-Alvarez D, Stoutenberg M, et al. Physical Activity Levels in U.S. Latino/Hispanic Adults: Results From the Hispanic Community Health Study/Study of Latinos. American journal of preventive medicine. 2016;50(4):500-508.

7. Holt CL, Tagai EK, Scheirer MA, et al. Translating evidence-based interventions for implementation: Experiences from Project HEAL in African American churches. Implementation science : IS. 2014;9:66.

8. Tristao Parra M, Porfirio GJM, Arredondo EM, Atallah AN. Physical Activity Interventions in Faith-Based Organizations: A Systematic Review. American journal of health promotion : AJHP. 2018;32(3):677-690.

9. Kegler MC, Escoffery C, Alcantara IC, Hinman J, Addison A, Glanz K. Perceptions of social and environmental support for healthy eating and physical activity in rural southern churches. Journal of religion and health. 2012;51(3):799-811.

10. Levin J. Engaging the faith community for public health advocacy: an agenda for the Surgeon General. Journal of religion and health. 2013;52(2):368-385.

11. Bopp M, Peterson JA, Webb BL. A Comprehensive Review of Faith-Based Physical Activity Interventions. American Journal of Lifestyle Medicine. 2012;6(6):460-478.

12. Levin J. Partnerships between the faith-based and medical sectors: Implications for preventive medicine and public health. Preventive medicine reports. 2016;4:344-350.

13. Rivera-Hernandez $M$. The role of religious leaders in health promotion for older Mexicans with diabetes. Journal of religion and health. 2015;54(1):303-315.

14. Campbell MK, Hudson MA, Resnicow K, Blakeney N, Paxton A, Baskin M. Church-based health promotion interventions: evidence and lessons learned. Annual review of public health. 2007;28:213234.

15. Glasgow RE, Lichtenstein E, Marcus AC. Why don't we see more translation of health promotion research to practice? Rethinking the efficacy-to-effectiveness transition. Am J Public Health. 2003;93(8):1261-1267.

16. Harden SM, Johnson SB, Almeida FA, Estabrooks PA. Improving physical activity program adoption using integrated research-practice partnerships: an effectiveness-implementation trial. Translational behavioral medicine. 2017;7(1):28-38.

17. Tabak RG, Khoong EC, Chambers DA, Brownson RC. Bridging research and practice: models for dissemination and implementation research. American journal of preventive medicine. 2012;43(3):337350.

18. Ramanadhan S, Davis MM, Armstrong R, et al. Participatory implementation science to increase the impact of evidence-based cancer prevention and control. Cancer causes \& control : CCC. 2018;29(3):363-369.

19. Arredondo EM, Haughton J, Ayala GX, et al. Fe en Accion/Faith in Action: Design and implementation of a church-based randomized trial to promote physical activity and cancer screening among churchgoing Latinas. Contemporary clinical trials. 2015;45(Pt B):404-415. 
20. Haughton J, Ayala GX, Burke KH, Elder JP, Montanez J, Arredondo EM. Community Health Workers Promoting Physical Activity: Targeting Multiple Levels of the Social Ecological Model. The Journal of ambulatory care management. 2015;38(4):309-320.

21. Arredondo EM, Elder JP, Haughton J, et al. Fe en Accion: Promoting Physical Activity Among Churchgoing Latinas. American journal of public health. 2017;107(7):1109-1115.

22. Conn VS, Hafdahl AR, Mehr DR. Interventions to increase physical activity among healthy adults: metaanalysis of outcomes. American journal of public health. 2011;101(4):751-758.

23. Wilcox S, Parrott A, Baruth $M$, et al. The Faith, Activity, and Nutrition program: a randomized controlled trial in African-American churches. American journal of preventive medicine. 2013;44(2):122-131.

24. Whitt-Glover MC, Goldmon MV, Gizlice Z, Sillice M, Hornbuckle L, Heil DP. Increasing Physical Activity in Black Women: Results from a Randomized Trial Conducted in Faith-Based Settings. Ethnicity \& disease. 2017;27(4):411-420.

25. Bopp M, Wilcox S, Laken M, et al. 8 Steps to Fitness: a faith-based, behavior change physical activity intervention for African Americans. Journal of physical activity \& health. 2009;6(5):568-577.

26. Gutierrez J, Devia C, Weiss L, et al. Health, community, and spirituality: evaluation of a multicultural faith-based diabetes prevention program. The Diabetes educator. 2014;40(2):214-222.

27. Yano EM. The role of organizational research in implementing evidence-based practice: QUERI Series. Implementation Science. 2008;3(1):29.

28. Beard M, Chuang E, Haughton J, Arredondo EM. Determinants of Implementation Effectiveness in a Physical Activity Program for Church-Going Latinas. Family \& community health. 2016;39(4):225-233.

29. Powers AR, Brock RW, Funderburk K, Parmer SM, Struempler B. Multilevel Faith-Based Public Health Initiative in Rural Alabama, 2017. Preventing chronic disease. 2019;16:E117.

30. Hardison-Moody A, Yao J. Faithful Families, Thriving Communities: Bridging Faith and Health Through a State-Level Partnership. American journal of public health. 2019;109(3):363-368.

31. Johnston JA, Konda K, Ablah E. Building Capacity Among Laity: A Faith-Based Health Ministry Initiative. Journal of religion and health. 2018;57(4):1276-1284.

32. Bopp M, Fallon EA. Health and wellness programming in faith-based organizations: a description of a nationwide sample. Health promotion practice. 2013;14(1):122-131.

33. Story CR, Knutson D, Brown JB, et al. Changes in social support over time in a faith-based physical activity intervention. Health education research. 2017;32(6):513-523.

34. Whitley MD, Payan DD, Florez KR, et al. Feasibility and acceptability of a mobile messaging program within a church-based healthy living intervention for African Americans and Latinos. Health Informatics J. 2019:1460458219853408.

35. Bopp M, Peterson JA, Webb BL. A Comprehensive Review of Faith-Based Physical Activity Interventions. 2012;6(6):460-478.

36. Kanu M, Baker E, Brownson RC. Exploring associations between church-based social support and physical activity. J Phys Act Health. 2008;5(4):504-515. 
37. Wilcox S, Saunders RP, Kaczynski AT, et al. Faith, Activity, and Nutrition Randomized Dissemination and Implementation Study: Countywide Adoption, Reach, and Effectiveness. American journal of preventive medicine. 2018;54(6):776-785.

38. Allen JD, Torres MI, Tom LS, Leyva B, Galeas AV, Ospino H. Dissemination of evidence-based cancer control interventions among Catholic faith-based organizations: results from the CRUZA randomized trial. Implementation science: IS. 2016;11(1):74.

39. Santos SL, Tagai EK, Scheirer MA, et al. Adoption, reach, and implementation of a cancer education intervention in African American churches. Implementation science : IS. 2017;12(1):36.

40. Allicock M, Campbell MK, Valle CG, Carr C, Resnicow K, Gizlice Z. Evaluating the dissemination of Body \& Soul, an evidence-based fruit and vegetable intake intervention: challenges for dissemination and implementation research. J Nutr Educ Behav. 2012;44(6):530-538.

41. Webb B, Bopp M, Fallon EA. A qualitative study of faith leaders' perceptions of health and wellness. Journal of religion and health. 2013;52(1):235-246.

42. Bernhart JA, Dunn CG, Wilcox S, Saunders RP, Sharpe PA, Stucker J. Church leaders' barriers and facilitators before and after implementing a physical activity and nutrition intervention. Health education research. 2019.

43. Damschroder LJ, Aron DC, Keith RE, Kirsh SR, Alexander JA, Lowery JC. Fostering implementation of health services research findings into practice: a consolidated framework for advancing implementation science. Implementation science : IS. 2009;4:50.

44. Keith RE, Crosson JC, O’Malley AS, Cromp D, Taylor EF. Using the Consolidated Framework for Implementation Research (CFIR) to produce actionable findings: a rapid-cycle evaluation approach to improving implementation. Implementation Science. 2017;12(1):15.

45. VanDevanter N, Kumar P, Nguyen N, et al. Application of the Consolidated Framework for Implementation Research to assess factors that may influence implementation of tobacco use treatment guidelines in the Viet Nam public health care delivery system. Implementation Science. $2017 ; 12(1): 27$.

46. Schell SF, Luke DA, Schooley MW, et al. Public health program capacity for sustainability: a new framework. Implementation science : IS. 2013;8:15.

47. Stewart J, Salas-Brooks J, Kelly B. Implementation of HIV Interventions Into Faith-Based Organizations: Models and Methodological Considerations. J Acquir Immune Defic Syndr. 2019;82 Suppl 3:S305-s313.

48. Center PR. The Shifting Religious Identify of Latinos in the United States. May 72014.

49. Clark L, Birkhead AS, Fernandez C, Egger MJ. A Transcription and Translation Protocol for Sensitive Cross-Cultural Team Research. Qual Health Res. 2017;27(12):1751-1764.

50. Tong A, Sainsbury P, Craig J. Consolidated criteria for reporting qualitative research (COREQ): a 32-item checklist for interviews and focus groups. International Journal for Quality in Health Care. 2007;19(6):349-357.

51. Miles MB, Huberman AM, Saldaña J. Qualitative Data Analysis: A Methods Sourcebook. Edition 3 ed. Thousan Oaks, California: SAGE Publications, Inc.; 2014. 
52. Saldaña J. Dramatizing data: a primer. Qualitative Inquiry. 2003;9(2):218-236.

53. Wolcott HF. Transforming Qualitative Data: Description, Analysis, and Interpretation. Thousan Oaks, California: SAGE Publications; 1994.

54. Saldaña J. The Coding Manual for Qualitative Researchers. Second Edition ed. London, England: SAGE Publications; 2013.

55. Gibbs GR. Analyzing Qualitative Data. London, England: SAGE Publications; 2007.

56. Powell BJ, Waltz TJ, Chinman MJ, et al. A refined compilation of implementation strategies: results from the Expert Recommendations for Implementing Change (ERIC) project. Implement Sci. 2015;10:21.

57. Proeschold-Bell RJ, McDevitt PJ. An overview of the history and current status of clergy health. $J$ Prev Interv Community. 2012;40(3):177-179.

58. Bopp M, Baruth M, Peterson JA, Webb BL. Leading their flocks to health? Clergy health and the role of clergy in faith-based health promotion interventions. Family \& community health. 2013;36(3):182-192.

59. Anshel MH, Smith $\mathrm{M}$. The role of religious leaders in promoting healthy habits in religious institutions. Journal of religion and health. 2014;53(4):1046-1059.

60. Cline KM, Ferraro KF. Does Religion Increase the Prevalence and Incidence of Obesity in Adulthood? Journal for the scientific study of religion. 2006;45(2):269-281.

61. Webb BL, Bopp M, Fallon EA. Correlates of faith leader physical activity behavior. Medicine \& Science in Sports \& Exercise. 2011;43(5):910.

62. Sack D. Whitebread Protestants: food and religion in American culture. New York, NY: Palgrave; 2000.

63. Hinings CR, Foster BD. The Organization Structure of Churches: A Preliminary Model. Sociology. 1973;7(1):93-106.

64. Pargament KI, Falgout K, Ensing DS, et al. The Congregation Development Program: Data-based consultation with churches and synagogues. Professional Psychology: Research and Practice. 1991;22(5):393-404.

65. Harmon BE, Strayhorn S, Webb BL, Hebert JR. Leading God's People: Perceptions of Influence Among African-American Pastors. Journal of religion and health. 2018;57(4):1509-1523.

66. Maton KI. Social support, organizational characteristics, psychological well-being, and group appraisal in three self-help group populations. American Journal of Community Psychology. 1988;16(1):53-77.

67. Baruth M, Wilcox S, Saunders RP. The role of pastor support in a faith-based health promotion intervention. Family \& community health. 2013;36(3):204-214.

68. Hanson RF, Schoenwald S, Saunders BE, et al. Testing the Community-Based Learning Collaborative (CBLC) implementation model: a study protocol. International journal of mental health systems. 2016;10:52.

69. Arredondo E, Mueller K, Mejia E, Rovira-Oswalder T, Richardson D, Hoos T. Advocating for environmental changes to increase access to parks: engaging promotoras and youth leaders. Health promotion practice. 2013;14(5):759-766. 
70. Harper CR, Kuperminc GP, Weaver SR, Emshoff J, Erickson S. Leveraged resources and systems changes in community collaboration. Am J Community Psychol. 2014;54(3-4):348-357.

71. Williams RM, Tagai EK, Santos SLZ, Slade JL, Carter RL, Holt CL. The Role of Leadership Support in a Church-Based Cancer Education Implementation Study. Journal of religion and health. 2018;57(1):146156.

72. Leyva B, Allen JD, Ospino H, et al. Enhancing capacity among faith-based organizations to implement evidence-based cancer control programs: a community-engaged approach. Translational behavioral medicine. 2017;7(3):517-528.

73. Guest G, Bunce A, Johnson L. How Many Interviews Are Enough?: An Experiment with Data Saturation and Variability. Field Methods. 2006;18(1):59-82.

\section{Tables}

Table 1. Barriers and facilitators to implementation of a faith-based physical activity program ( $\mathrm{n}=22)$

\begin{tabular}{lll}
\hline CFIR domain & $\begin{array}{l}\text { Barriers \& Facilitators to } \\
\text { Implementation }\end{array}$ & Seminal quote \\
\hline
\end{tabular}

Characteristics

of Individuals 1. Pastors/staff lack selfefficacy for and knowledge of PA

"They never taught us that in priest school."

"[The pastor] is a half-marathon runner, he's being a little modest but you know they always see him in his warm up suit -

2. Pastors have influence over people get more motivated."

churchgoers' behaviors

Inner Setting -

Culture
1. Churches can support a culture of overeating and unhealthy behaviors

2. Churches implement programs aligned with their mission and values

3. Church culture and norms are influenced by pastors and staff
"[In] the Hispanic culture everything is about food because you know when they sit around food they talk, fellowship, very intimate for people."

"We can't do everything, we want to keep us focused on doing the things that we know, that we should be focused on to make our vision a reality."

"I get in trouble because I say 'you know what some of us don't look like temples we look like cathedrals."
Inner Setting -

Implementation 1. Churches have many

Climate competing priorities

2. Many churches lack sufficient space and personnel

3. Programs typically come from within the church
"You know, there are many programs out there, really good programs."

"The first thing the pastor wants to know is, is this going to be more work for me?"

"One of the things we don't do a lot is have somebody from the outside come in and start a ministry."
Outer Setting

1. Denominational support is critical for program success
"Well if you could get it to come from the top because I will be there but a lot of [pastors who] won't find the time unless it's coming from the Diocese." 
Table 2. Proposed Implementation Strategies for Faith-Based Health Promotion Programs.

\begin{tabular}{|c|c|c|c|}
\hline $\begin{array}{l}\text { Implementation } \\
\text { Strategy - } \\
\text { ERIC }{ }^{56} \text { strategy }\end{array}$ & $\begin{array}{l}\text { Barriers to } \\
\text { Implementation }\end{array}$ & $\begin{array}{l}\text { Facilitators to } \\
\text { Implementation }\end{array}$ & Mechanisms of Action \\
\hline $\begin{array}{l}\text { (1) Health Behavior } \\
\text { Change Training - } \\
\text { Training \& } \\
\text { Education }\end{array}$ & $\begin{array}{l}\text { Pastors lack self- } \\
\text { efficacy for PA }\end{array}$ & $\begin{array}{l}\text { Pastors influence } \\
\text { churchgoers' behaviors }\end{array}$ & $\begin{array}{l}\text { Pastors' increased self-efficacy for PA; } \\
\text { pastors role model healthy behaviors, } \\
\text { including PA }\end{array}$ \\
\hline $\begin{array}{l}\text { (1) Health Behavior } \\
\text { Change Training - } \\
\text { Education }\end{array}$ & $\begin{array}{l}\text { Pastors lack } \\
\text { knowledge in } \\
\text { promoting PA }\end{array}$ & $\begin{array}{l}\text { Pastors provide } \\
\text { individual-level } \\
\text { counseling to } \\
\text { members }\end{array}$ & $\begin{array}{l}\text { Pastors encourage churchgoers to be } \\
\text { active and healthy (e.g., praise those } \\
\text { who meet PA goals) }\end{array}$ \\
\hline $\begin{array}{l}\text { (1) Health Behavior } \\
\text { Change Training - } \\
\text { Motivate Change }\end{array}$ & $\begin{array}{l}\text { Churches can support } \\
\text { culture of overeating } \\
\text { and unhealthy } \\
\text { behaviors }\end{array}$ & $\begin{array}{l}\text { Pastors influence } \\
\text { church culture and } \\
\text { norms }\end{array}$ & $\begin{array}{l}\text { Pastors implement policies that } \\
\text { promote health (e.g., healthy tips in } \\
\text { church bulletins); establish a health } \\
\text { ministry }\end{array}$ \\
\hline $\begin{array}{l}\text { (2) Tailored } \\
\text { Messaging - Tailor } \\
\text { Strategies }\end{array}$ & $\begin{array}{l}\text { Programs typically } \\
\text { come from within the } \\
\text { church }\end{array}$ & $\begin{array}{l}\text { Churches implement } \\
\text { programs that are } \\
\text { aligned with their } \\
\text { mission }\end{array}$ & $\begin{array}{l}\text { Pastors consider the program to be } \\
\text { relevant (e.g., social justice) to them } \\
\text { and the church }\end{array}$ \\
\hline $\begin{array}{l}\text { (3) Foster } \\
\text { Community } \\
\text { Collaboration - } \\
\text { Develop Partnerships }\end{array}$ & $\begin{array}{l}\text { Churches lack } \\
\text { sufficient space and } \\
\text { personnel for } \\
\text { programming }\end{array}$ & $\begin{array}{l}\text { Local organizations } \\
\text { with capacity for PA } \\
\text { programming }\end{array}$ & $\begin{array}{l}\text { Stronger collaborations with local } \\
\text { organizations (e.g., joint projects, } \\
\text { sharing resources/staff) }\end{array}$ \\
\hline $\begin{array}{l}\text { (4) Gain } \\
\text { Denominational } \\
\text { Support - Involve } \\
\text { Executive Leadership }\end{array}$ & $\begin{array}{l}\text { Denominational } \\
\text { support is needed for } \\
\text { a program to succeed }\end{array}$ & $\begin{array}{l}\text { Denominational } \\
\text { support can lead to } \\
\text { wider scale-up }\end{array}$ & $\begin{array}{l}\text { Denominational leadership (e.g., } \\
\text { Diocese) encourages pastors to } \\
\text { promote PA in churches }\end{array}$ \\
\hline
\end{tabular}

\section{Supplementary Files}

This is a list of supplementary files associated with this preprint. Click to download.

- A1.Interviewguide02072020.docx

- A1.Interviewguide02072020.docx

- A2.COREQchecklist02092020.docx

- A2.COREQchecklist02092020.docx 